American J. of Engineering and Applied Sciences 1 (2): 141-148, 2008

ISSN 1941-7020

(C) 2008 Science Publications

\title{
Analytical Solution of Temperature Field in Hollow Cylinder under Time Dependent Boundary Condition Using Fourier series
}

\author{
Golamali atefi, Mohammad Ali Abdous, Abdolsaeid Ganjehkaviri \\ Iran University of Science and Technology, Iran
}

\begin{abstract}
The objective of this study is to derive an analytical solution of one dimensional heat conduction equation applied in a hollow cylinder, which is subjected to a periodic boundary condition at the outer surface while the inner surface is insulated. The material is assumed to be homogenous and isotropic with time-independent thermal properties. Because of the time-dependent term in the boundary condition, Duhamel's theorem is used to solve the problem for a periodic boundary condition. The periodic boundary condition is decomposed by Fourier series. The obtained temperature distribution contains two characteristics, the dimensionless amplitude and the dimensionless phase difference. These results were plotted with respect to Biot and Fourier numbers. The agreement between our results and the former work that was related to one dimensional solution of infinite, solid cylinder, under simple harmonic condition was realized to be very good.
\end{abstract}

Key words: Hollow cylinder, periodic boundary condition, heat conduction

\section{INTRODUCTION}

There were a lot of researches for calculating the temperature field in various shapes using different boundary and initial conditions. In 1947, Hessler ${ }^{[1]}$ obtained unstable temperature field in a long solid cylinder, solid sphere and infinite flat plate, with homogenous boundary condition. Also, Özisik ${ }^{[2]}$ determined the unstable temperature field in hollow and solid cylinder under the periodic boundary condition. Troste $^{[3]}$ gained stresses field created by different temperature distribution. $\mathrm{VDI}^{[4]}$ presented the calculation of periodic boundary condition which is simulated by harmonic oscillation of ambient temperature.

\section{MATHEMATICAL MODEL}

The heat conduction equation for a cylinder, without heat source and homogenous properties is expressed as:

$$
\frac{1}{\mathrm{a}} \frac{\partial \theta}{\partial \mathrm{t}}=\nabla^{2} \theta=\frac{\partial^{2} \theta}{\partial \mathrm{r}^{2}}+\frac{1}{\mathrm{r}} \frac{\partial \theta}{\partial \mathrm{r}}
$$

The outer boundary condition is general and the inner one is insulated:

$$
\left\{\begin{array}{l}
\theta\left(\mathrm{r}_{\mathrm{o}}, \mathrm{t}\right)+\left.\frac{\mathrm{k}}{\mathrm{h}} \frac{\partial \theta}{\partial \mathrm{r}}\right|_{\mathrm{r}_{0}, \mathrm{t}}=\mathrm{g}_{0}(\mathrm{t}) \\
\left.\frac{\partial \theta}{\partial \mathrm{r}}\right|_{\mathrm{r}_{\mathrm{i}}, \mathrm{t}}=0
\end{array}\right.
$$

$\mathrm{g}_{0}(\mathrm{t})$ is considered to be a periodic function which is decomposed using Fourier series:

$$
\mathrm{g}_{0}(\mathrm{t})=\sum_{\mathrm{n}=1}^{\infty} \theta_{\mathrm{n}} \operatorname{Sin}\left(2 \mathrm{n} \pi \frac{\mathrm{t}}{T}\right)
$$

\section{ANALYTICAL SOLUTION}

With considering Eq. 2 the problem can't be solved directly. So the Equation should be solved with assumption that, the boundary condition is timeindependent. In this situation the boundary and initial conditions are:

$$
\left\{\begin{array}{l}
\theta\left(\mathrm{r}_{\mathrm{o}}\right)+\left.\frac{\mathrm{k}}{\mathrm{h}} \frac{\partial \theta}{\partial \mathrm{r}}\right|_{\mathrm{r}_{\mathrm{o}}}=\mathrm{g}_{0} \\
\left.\frac{\partial \theta}{\partial \mathrm{r}}\right|_{\mathrm{r}_{\mathrm{i}}}=0
\end{array}\right.
$$

$$
\theta(r, 0)=0
$$


It is assumed that there are two solutions for solving the problem; the first one is for steady state condition $\theta_{0}(r)$ and the second one for unsteady state condition $\theta_{1}(\mathrm{r}, \mathrm{t})$ :

$$
\theta(\mathrm{r}, \mathrm{t})=\theta_{0}(\mathrm{r})+\theta_{1}(\mathrm{r}, \mathrm{t})
$$

The differential heat conduction equation in steady state condition is:

$$
\nabla^{2} \theta_{0}=\frac{\partial^{2} \theta_{0}}{\partial \mathrm{r}^{2}}+\frac{1}{\mathrm{r}} \frac{\partial \theta_{0}}{\partial \mathrm{r}}=0
$$

Where the boundary conditions are given by Eq. 4 and Eq. 5. The transient differential equation is:

$$
\frac{1}{\mathrm{a}} \frac{\partial \theta}{\partial \mathrm{t}}=\nabla^{2} \theta=\frac{\partial^{2} \theta}{\partial \mathrm{r}^{2}}+\frac{1}{\mathrm{r}} \frac{\partial \theta}{\partial \mathrm{r}}
$$

And these conditions must be satisfied:

$$
\begin{gathered}
\theta_{1}\left(\mathrm{r}_{\mathrm{o}}, \mathrm{t}\right)+\left.\frac{\mathrm{k}}{\mathrm{h}} \frac{\partial \theta_{1}}{\partial \mathrm{r}}\right|_{\mathrm{r}_{\mathrm{o}}, \mathrm{t}}=0 \\
\frac{\partial \theta_{1}}{\left.\partial \mathrm{r}\right|_{\mathrm{r}_{\mathrm{i}}, \mathrm{t}}}=0 \\
\theta(\mathrm{r}, 0)=0 \\
\theta_{0}(\mathrm{r})=-\theta_{1}(\mathrm{r}, 0)
\end{gathered}
$$

Steady state problem: With solving Eq. 7, the differential equation in radial direction is obtained:

$$
\frac{\partial^{2} \mathrm{R}}{\partial \mathrm{r}^{2}}+\frac{1}{\mathrm{r}} \frac{\partial \mathrm{R}}{\partial \mathrm{r}}=0
$$

Solution for Eq. 12 becomes:

$$
\mathrm{R}(\mathrm{r})=\mathrm{C}_{1}+\mathrm{C}_{2} \log (\mathrm{r})
$$

So, general solution in this state is:

$$
\theta_{0}(\mathrm{r})=\mathrm{g}_{0}
$$

Transient problem: Applying separation of variables method for solving Eq. 8:

$$
\begin{aligned}
& \mathrm{R}^{\prime \prime}+\frac{1}{\mathrm{r}} \mathrm{R}^{\prime}=-\mu^{2} \mathrm{R} \\
& \frac{\mathrm{T}^{\prime}}{\mathrm{T}}=-\mathrm{a} \mu^{2}
\end{aligned}
$$

Solutions for above differential equations respectively, are:

$$
R(r)=A_{2} J_{0}(\mu r)+B_{2} Y_{0}(\mu r)
$$

$$
\mathrm{T}(\mathrm{t})=\mathrm{A}_{0} \mathrm{e}^{-\mathrm{a \mu}^{2} \mathrm{t}}
$$

By assuming two new coefficients:

$$
\begin{aligned}
& \mathrm{A}_{0} \mathrm{~A}_{2}=\mathrm{C}_{1} \\
& \mathrm{~A}_{0} \mathrm{~B}_{2}=\mathrm{C}_{2}
\end{aligned}
$$

So, transient state solution is:

$$
\theta_{1}(r, t)=e^{-a \mu^{2} t}\left[C_{1} J_{0}(\mu r)+C_{2} Y_{0}(\mu r)\right]
$$

By considering Eq. 9:

$$
\begin{aligned}
& C_{1}\left[J_{0}\left(\mu_{j} r_{o}\right)+\frac{k}{h} \mu_{j} J_{0}^{\prime}\left(\mu_{j} r_{o}\right)\right]+ \\
& C_{2}\left[Y_{0}\left(\mu_{j} r_{o}\right)+\frac{k}{h} \mu_{j} Y_{0}^{\prime}\left(\mu_{j} r_{o}\right)\right]=0 \\
& C_{1} J_{0}^{\prime}\left(\mu_{j} r_{i}\right)+C_{2} Y_{0}^{\prime}\left(\mu_{j} r_{i}\right)=0
\end{aligned}
$$

For having solution, the determinant of Eq. 22 and Eq. 23 must be zero:

$$
\begin{aligned}
& {\left[\mathrm{J}_{0}\left(\mu_{\mathrm{j}} \mathrm{r}_{\mathrm{o}}\right)+\frac{\mathrm{k}}{\mathrm{h}} \mu_{\mathrm{j}} \mathrm{J}_{0}^{\prime}\left(\mu_{\mathrm{j}} \mathrm{r}_{\mathrm{o}}\right)\right] \mathrm{Y}_{0}^{\prime}\left(\mu_{\mathrm{j}} \mathrm{r}_{\mathrm{i}}\right)-} \\
& \mathrm{J}_{0}^{\prime}\left(\mu_{\mathrm{j}} \mathrm{r}_{\mathrm{i}}\right)\left[\mathrm{Y}_{0}\left(\mu_{\mathrm{j}} \mathrm{r}_{\mathrm{o}}\right)+\frac{\mathrm{k}}{\mathrm{h}} \mu_{\mathrm{j}} \mathrm{Y}_{0}^{\prime}\left(\mu_{\mathrm{j}} \mathrm{r}_{\mathrm{o}}\right)\right]=0
\end{aligned}
$$

From Eq. 24 the $\mu_{\mathrm{j}}$ coefficients are found. On the other hand, From Eq. 23 the relationship between $\mathrm{C}_{1}$, $\mathrm{C}_{2}$ is obtained:

$$
\mathrm{C}_{2}=-\frac{\mathrm{J}_{0}^{\prime}\left(\mu_{\mathrm{j}} \mathrm{r}_{\mathrm{i}}\right)}{\mathrm{Y}_{0}^{\prime}\left(\mu_{\mathrm{j}} \mathrm{r}_{\mathrm{i}}\right)} \mathrm{C}_{1}
$$

So, the solution in radial direction is:

$$
R(r)=C_{1}\left[J_{0}\left(\mu_{j} r\right)-\frac{J_{0}^{\prime}\left(\mu_{j_{i}}\right)}{Y_{0}^{\prime}\left(\mu_{j} r_{i}\right)} Y_{0}\left(\mu_{j} r\right)\right]
$$

Then, the solution for transient temperature distribution is: 


$$
\theta_{1}(r, t)=\sum_{j=0}^{\infty} C_{j}\left(J_{0}\left(\mu_{j} r\right)-\frac{J_{0}^{\prime}\left(\mu_{j_{i}}\right)}{Y_{0}^{\prime}\left(\mu_{j} r_{i}\right)} Y_{0}\left(\mu_{j} r\right)\right) e^{-a \mu_{j}^{2} t}
$$

For simplifying, the transient solution we assumed:

$$
\Phi\left(\mu_{\mathrm{j}} \mathrm{r}\right)=\frac{\mathrm{J}_{0}\left(\mu_{\mathrm{j}} \mathrm{r}\right) \mathrm{Y}_{0}^{\prime}\left(\mu_{\mathrm{j}} \mathrm{r}_{\mathrm{i}}\right)-\mathrm{J}_{0}^{\prime}\left(\mu_{\mathrm{j}} \mathrm{r}_{\mathrm{i}}\right) \mathrm{Y}_{0}\left(\mu_{\mathrm{j}} \mathrm{r}\right)}{\mathrm{Y}_{0}^{\prime}\left(\mu_{\mathrm{j}} \mathrm{r}_{\mathrm{i}}\right)}
$$

Then, the transient state solution is:

$$
\theta_{1}(r, t)=\sum_{j=0}^{\infty} C_{j} \Phi\left(\mu_{j} r\right) e^{-a \mu_{j}^{2} t}
$$

By applying Eq. 11 the coefficient $C_{j}$ is found:

$$
\sum_{\mathrm{j}=0}^{\infty} \mathrm{C}_{\mathrm{j}} \Phi\left(\mu_{\mathrm{j}} \mathrm{r}\right)=-\mathrm{g}_{0}
$$

Using the orthogonality of eigen function $\Phi\left(\mu_{\mathrm{j}} \mathrm{r}\right)$ :

$$
\begin{gathered}
\int_{r_{i}}^{r_{0}} r \Phi\left(\mu_{i} r\right) \Phi\left(\mu_{j} r\right) d r=0 \quad i \neq j \\
\int_{r_{i}}^{r_{0}} r \Phi^{2}\left(\mu_{j} r\right) d r=\left[\frac{r^{2}}{2}\left[\Phi\left(\mu_{j} r\right)^{2}+\Phi^{\prime}\left(\mu_{j} r\right)^{2}\right]\right]_{r_{i}}^{r_{0}} \quad i=j
\end{gathered}
$$

For obtaining $C_{j}$ the both side of Eq. 30 must be multiplied by $r \Phi\left(\mu_{j} r\right)$ and integrate from $r_{i}$ to $r_{o}$ :

$$
C_{j}=-\frac{g_{0} \int_{r_{i}}^{r_{0}} r \Phi\left(\mu_{j} r\right) d r}{\left[\frac{r^{2}}{2}\left[\Phi\left(\mu_{j} r\right)^{2}+\Phi^{\prime}\left(\mu_{j} r\right)^{2}\right]\right]_{r_{i}}^{r_{0}}}
$$

So, the transient temperature distribution is:

$$
\theta_{1}(r, t)=\sum_{j=0}^{\infty} C_{j} \Phi\left(\mu_{j} r\right) e^{-a \mu_{j}^{2} t}
$$

Finally, the temperature distribution becomes:

$$
\begin{gathered}
\theta(\mathrm{r}, \mathrm{t})=\theta_{0}(\mathrm{r})+\theta_{1}(\mathrm{r}, \mathrm{t}) \\
\theta(\mathrm{r}, \mathrm{t})=\mathrm{g}_{0}-\sum_{\mathrm{j}=0}^{\infty} \frac{\mathrm{g}_{0} \int_{\mathrm{r}_{\mathrm{i}}}^{\mathrm{r}_{\mathrm{o}}} \mathrm{r} \Phi\left(\mu_{\mathrm{j}} \mathrm{r}\right) \mathrm{dr}}{\left.\frac{\mathrm{r}^{2}}{2}\left[\Phi\left(\mu_{\mathrm{j}} \mathrm{r}\right)^{2}+\Phi^{\prime}\left(\mu_{\mathrm{j}} \mathrm{r}\right)^{2}\right]\right]_{\mathrm{r}_{\mathrm{i}}}^{\mathrm{r}_{\mathrm{o}}}} \Phi\left(\mu_{\mathrm{j}} \mathrm{r}\right) \mathrm{e}^{-\mathrm{a \mu} \mu_{\mathrm{j}} \mathrm{t} t}
\end{gathered}
$$

The temperature field under time varying boundary condition:

Equation 36 expresses the temperature field under time-independent boundary condition. The $\mathrm{g}_{0}$ is independent on time. In the case that the boundary value depends on time, it has the variation in the form:

$$
\operatorname{dg}_{0}=\frac{\mathrm{dg}_{0}}{\mathrm{~d} \tau} \mathrm{d} \tau
$$

It can be considered the changing occurs at time $\tau$ is constant. Thus the temperature distribution after time $\mathrm{t}-\tau$ seconds after starting the influences can be expressed in:

$$
\begin{aligned}
& \mathrm{d} \theta(\mathrm{r}, \mathrm{t})=\left(1-\sum_{\mathrm{j}=0}^{\infty} \frac{\int_{\mathrm{r}_{\mathrm{i}}}^{\mathrm{r}_{\mathrm{o}}} \mathrm{r} \Phi\left(\mu_{\mathrm{j}} \mathrm{r}\right) \mathrm{dr}}{\left.\frac{\mathrm{r}^{2}}{2}\left[\Phi\left(\mu_{\mathrm{j}} \mathrm{r}\right)^{2}+\Phi^{\prime}\left(\mu_{\mathrm{j}} \mathrm{r}\right)^{2}\right]\right]_{\mathrm{r}_{\mathrm{i}}}^{\mathrm{r}_{\mathrm{o}}}}\right. \\
& \left.\Phi\left(\mu_{\mathrm{j}} \mathrm{r}\right) \mathrm{e}^{-\mathrm{a \mu} \mu_{\mathrm{j}} \mathrm{t}}\right) \frac{\mathrm{dg}}{\mathrm{d} \tau} \mathrm{d} \tau
\end{aligned}
$$

Thus, the temperature field can be obtained by summation of $\mathrm{dg}_{0}$ during $\mathrm{d} \tau$ and the influence of $\mathrm{g}_{0}(0)$. The following equation is proven by the method of integration by parts:

$$
\begin{aligned}
& \mathrm{g}_{0}(0) \mathrm{e}^{-\mathrm{a \mu} \mu_{j}^{2} t}+\int_{\tau=0}^{\mathrm{t}} \mathrm{e}^{-\mathrm{a \mu} \mathrm{\mu}_{j}^{2}(\mathrm{t}-\tau)} \frac{d g_{0}}{\mathrm{~d} \tau} d \tau \\
& =\mathrm{g}_{0}(\mathrm{t})-\mathrm{a} \mu_{\mathrm{j}}^{2} \int_{\tau=0}^{\mathrm{t}} \mathrm{g}_{0}(\tau) \mathrm{e}^{-\mathrm{a \mu \mu _{j } ^ { 2 }}(\mathrm{t}-\tau)} \mathrm{d} \tau
\end{aligned}
$$

Using of Eq. 39, the temperature field can be obtained in the form:

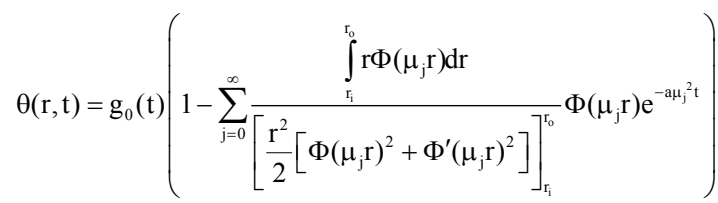

$$
+\sum_{j=0}^{\infty} a \mu_{j}^{2} \frac{\int_{r_{i}}^{r_{0}} r \Phi\left(\mu_{j} r\right) d r}{\left[\frac{r^{2}}{2}\left[\Phi\left(\mu_{j} r^{2}+\Phi^{\prime}\left(\mu_{j}\right)^{2}\right]\right]_{r_{i}}^{r_{0}}\right.} \Phi\left(\mu_{j} r\right) \int_{\tau=0}^{t} g_{0}(\tau) e^{-a \mu_{j}^{2}(t-\tau)} d \tau
$$

The first term of Eq. 40 is zero because it includes the expansion of constant function 1 in terms of $\Phi\left(\mu_{j} r\right)$, therefore the simplified form of Eq. 40 becomes: 


$$
\begin{aligned}
& \theta(r, t)=\sum_{j=0}^{\infty} a \mu_{j}^{2} \frac{\int_{r_{i}}^{r_{0}} r\left(\mu_{j} r\right) d r}{\left[\frac{r^{2}}{2}\left[\Phi\left(\mu_{j} r\right)^{2}+\Phi^{\prime}\left(\mu_{j} r\right)^{2}\right]\right]_{r_{i}}^{r_{0}}} \\
& \Phi\left(\mu_{j} r\right) \int_{\tau=0}^{t} \sum_{n=1}^{\infty} \theta_{n} \operatorname{Sin}\left(2 n \pi \frac{\tau}{T}\right) e^{-a \mu_{j}^{2}(t-\tau)} d \tau
\end{aligned}
$$

Then, the temperature distribution field becomes:

$$
\theta(r, t)=\sum_{j=0}^{\infty} D_{j} T_{j}(t) \Phi\left(\mu_{j} r\right)
$$

Where, $T_{j}(t)$ and $D_{j}$ are:

$$
\begin{gathered}
\mathrm{T}_{\mathrm{j}}(\mathrm{t})=\mathrm{a} \mu_{\mathrm{j}}^{2} \int_{\tau=0}^{\mathrm{t}} \int_{\mathrm{r}_{\mathrm{i}}}^{\mathrm{r}_{\mathrm{o}}} \mathrm{r} \Phi\left(\mu_{\mathrm{j}} \mathrm{r}\right) \sum_{\mathrm{n}=1}^{\infty} \theta_{\mathrm{n}} \operatorname{Sin}\left(2 \mathrm{n} \pi \frac{\tau}{\mathrm{T}}\right) \mathrm{e}^{-\mathrm{a \mu} \mathrm{j}_{j}^{2}(\mathrm{t}-\tau)} \mathrm{drd} \tau \\
\mathrm{D}_{\mathrm{j}}=\frac{1}{\left[\frac{\mathrm{r}^{2}}{2}\left[\Phi\left(\mu_{\mathrm{j}} \mathrm{r}\right)^{2}+\Phi^{\prime}\left(\mu_{\mathrm{j}} \mathrm{r}\right)^{2}\right]\right]_{\mathrm{r}_{\mathrm{i}}}^{\mathrm{r}_{\mathrm{o}}}}
\end{gathered}
$$

For simplifying Eq. 42 and plotting the result, we must rewrite our result in dimensionless form. With assuming dimensionless numbers below:

$$
\overline{\mathrm{r}}=\frac{\mathrm{r}}{\mathrm{r}_{\mathrm{o}}}, \overline{\mathrm{t}}=\frac{\mathrm{t}}{\mathrm{T}}, \mathrm{Bi}=\frac{\mathrm{hr}}{\mathrm{k}}, \mathrm{Fo}=\frac{\mathrm{aT}}{\mathrm{r}_{\mathrm{o}}^{2}}, \mathrm{~m}=\frac{\mathrm{r}_{\mathrm{i}}}{\mathrm{r}_{\mathrm{o}}}
$$

Where, $\overline{\mathrm{r}}, \overline{\mathrm{t}}, m, B i, F o$ are dimensionless radius, dimensionless time, dimensionless thickness, Biot and Fourier numbers, respectively.

Then $T_{j}(\bar{t})$ and $D_{j}$ become:

$$
\begin{gathered}
\gamma_{\mathrm{j}}=\int_{\mathrm{m}}^{1} \overline{\mathrm{r}} \Phi\left(\mu_{\mathrm{j}} \overline{\mathrm{r}}\right) \mathrm{d} \overline{\mathrm{r}} \\
\mathrm{T}_{\mathrm{j}}(\overline{\mathrm{t}})=\text { Fo. } \gamma_{\mathrm{j}} \mu_{\mathrm{j}}^{2} \int_{\tau=0}^{\overline{\mathrm{f}}} \sum_{\mathrm{n}=1}^{\infty} \theta_{\mathrm{n}} \operatorname{Sin}(2 \mathrm{n} \pi \overline{\mathrm{t}}) \mathrm{e}^{-\mathrm{Fo} \mu_{j}^{2}(\overline{\mathrm{t}}-\tau)} \mathrm{d} \tau \\
\mathrm{D}_{\mathrm{j}}=\frac{1}{\left[\frac{\overline{\mathrm{r}}}{2}\left[\Phi\left(\mu_{\mathrm{j}} \overline{\mathrm{r}}\right)^{2}+\Phi^{\prime}\left(\mu_{\mathrm{j}} \overline{\mathrm{r}}\right)^{2}\right]\right]_{\mathrm{m}}^{1}} \\
\left.\theta(\overline{\mathrm{r}, \overline{\mathrm{t}}})=\sum_{\mathrm{j}=0}^{\infty} \mathrm{D}_{\mathrm{j}} \mathrm{T}_{\mathrm{j}} \overline{\mathrm{t}}\right) \Phi\left(\mu_{\mathrm{j}} \overline{\mathrm{r}}\right)
\end{gathered}
$$

In Eq. 47 when $(\overline{\mathrm{t}} \rightarrow \infty)$ the steady state temperature is obtained:

$$
\mathrm{T}_{\mathrm{j}}(\overline{\mathrm{t}})=\gamma_{\mathrm{j}} \sum_{\mathrm{n}=1}^{\infty} \frac{\theta_{\mathrm{n}}}{\sqrt{1+\left(\frac{2 \mathrm{nM}^{2}}{\mu_{\mathrm{j}}^{2}}\right)^{2}}} \sin \left(2 \mathrm{n} \pi \overline{\mathrm{t}}+\varphi_{\mathrm{jn}}\right)
$$

$$
\mathrm{M}=\sqrt{\frac{\pi}{\mathrm{Fo}_{\mathrm{O}}}}
$$

$$
\varphi_{\mathrm{jn}}=\operatorname{Arctan}\left(-\frac{2 \mathrm{nM}^{2}}{\mu_{\mathrm{j}}^{2}}\right)
$$

Then, the temperature distribution field becomes:

$$
\begin{aligned}
& \theta(\overline{\mathrm{r}}, \overline{\mathrm{t}})=\sum_{\mathrm{j}=0}^{\infty} \frac{\Phi\left(\mu_{\mathrm{j}} \overline{\mathrm{r}}\right) \gamma_{\mathrm{j}}}{\left[\frac{\overline{\mathrm{r}}}{2}\left[\Phi\left(\mu_{\mathrm{j}} \overline{\mathrm{r}}\right)^{2}+\Phi^{\prime}\left(\mu_{\mathrm{j}} \overline{\mathrm{r}}\right)^{2}\right]\right]_{\mathrm{m}}^{1}} \\
& \sum_{\mathrm{n}=1}^{\infty} \frac{\theta_{\mathrm{n}}}{\sqrt{1+\left(\frac{2 \mathrm{nM}^{2}}{\mu_{\mathrm{j}}^{2}}\right)^{2}}} \sin \left(2 \mathrm{n} \pi \overline{\mathrm{t}}+\varphi_{\mathrm{jn}}\right)
\end{aligned}
$$

Therefore, the final result becomes:

$$
\theta(\overline{\mathrm{r}, \overline{\mathrm{t}}})=\sum_{\mathrm{j}=0}^{\infty} \sum_{\mathrm{n}=1}^{\infty} \mathrm{A}_{\mathrm{jn}} \theta_{\mathrm{n}} \operatorname{Sin}\left(2 \mathrm{n} \pi \overline{\mathrm{t}}+\varphi_{\mathrm{jn}}\right)
$$

$\mathrm{A}_{\mathrm{jn}}$ is the ratio of the oscillation amplitude of temperature distribution field in the hollow cylinder and the ambient temperature with the same frequency and $\varphi_{\mathrm{jn}}$ is the phase difference. By calculating and plotting Eq. (55), the maximum of the amplitude of summation of harmonic waves and the phase difference can be obtained.

Obtaining an expression for heat flux: The heat flux per meter passes from the outer surface of hollow cylinder is:

$$
d Q=\rho C(\theta(r, 0)-\theta(r, t)) d A
$$

Where $d A$ is:

$$
\mathrm{dA}=2 \pi \mathrm{rdr}
$$

Then $\mathrm{Q}(\mathrm{t})$ becomes: 


$$
Q(t)=-2 \pi \rho C \int_{r_{i}}^{r_{0}} \theta(r, t) r d r
$$

The dimensionless form of $\mathrm{Q}(\mathrm{t})$ becomes:

$$
\mathrm{Q}(\overline{\mathrm{t}})=-2 \pi \rho \mathrm{Cr}_{0}^{2} \int_{\mathrm{m}}^{1} \theta(\overline{\mathrm{r}, \overline{\mathrm{t}}) \overline{\mathrm{rdr}}} \overline{\mathrm{r}}
$$

With substitution of $\theta(\overline{\mathrm{r}, \overline{\mathrm{t}}})$ in Eq. 59:

$$
\begin{aligned}
& \mathrm{Q}(\overline{\mathrm{t}})=-2 \pi \rho \mathrm{Cr}_{\mathrm{o}}^{2} \sum_{\mathrm{j}=0}^{\infty} \frac{\gamma_{\mathrm{j}} \int_{\mathrm{m}}^{1} \mathrm{r} \Phi\left(\mu_{\mathrm{j}} \overline{\mathrm{r}}\right) \mathrm{dr}}{\left.\frac{\mathrm{r}^{2}}{2}\left[\Phi\left(\mu_{\mathrm{j}} \overline{\mathrm{r}}\right)^{2}+\Phi^{\prime}\left(\mu_{\mathrm{j}} \overline{\mathrm{r}}\right)^{2}\right]\right]_{\mathrm{m}}^{1}} \\
& \sum_{\mathrm{n}=1}^{\infty} \frac{\theta_{\mathrm{n}}}{\sqrt{1+\left(\frac{2 \mathrm{nM}^{2}}{\mu_{\mathrm{j}}^{2}}\right)^{2}}} \sin \left(2 \mathrm{n} \pi \overline{\mathrm{t}}+\varphi_{\mathrm{jn}}\right)
\end{aligned}
$$

\section{RESULTS AND DISCUSSION}

As it was explained, the temperature distribution field in hollow cylinder recognized with two characteristics. The dimensionless amplitude $A$ and the dimensionless phase difference $\varphi$. It could be possible that with these two quantities, we can understand the temperature field oscillates with what phase difference and the ratio of amplitude, with respect to ambient temperature in hollow cylinder. In Fig.1-Fig.10 the variation of $A$ and $\varphi$ with respect to dimensionless number $M$ and $B i / M$ is considered. $M$ is proportional to frequency of oscillations of temperature and inverse square of Fourier number $(\mathrm{Fo})$. Also $\mathrm{Bi} / \mathrm{M}$ takes effect from environmental condition, period of oscillation and thermo physic characteristic of hollow cylinder. The $\mathrm{g}_{0}(\mathrm{t})$ is an arbitrary function, which is expanded by Fourier series. For special case, the dimensionless amplitude and dimensionless phase difference for function $\mathrm{g}_{0}(\mathrm{t})=\theta_{0}+\left(\theta_{\infty, \max }-\bar{\theta}\right) \mathrm{A}_{0} \operatorname{Sin}\left(2 \pi \frac{\mathrm{t}}{\mathrm{T}}+\varphi_{0}\right)$ is calculated and compared with VDI ${ }^{[4]}$ for solid, infinite cylinder. Comparison between our result and VDI ${ }^{[4]}$ show a very good agreement as shown in Figs. 1 and 2.

The effect of dimensionless number $(M)$ on $A$ and $\varphi$ of temperature field: In Fig. 1 and Fig. 2 it is assumed that $\overline{\mathrm{r}}=1, \mathrm{~m}=0$. In Fig.1 dimensionless amplitude is presented. For small values of $M$ (small frequencies of ambient temperature) the rate of energy storage in hollow cylinder is low and the rate of heat conduction is high conduction is high. So, the dimensionless amplitude $A$ is 1 . Also in Fig. 2 the phase difference is zero.

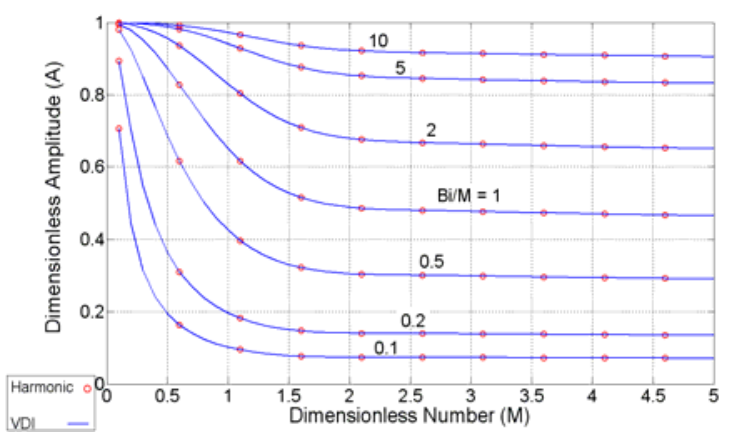

Fig. 1: Comparison between the result of the dimensionless amplitude, $A$ of temperature field of a solid cylinder ${ }^{[4]}$ and our result

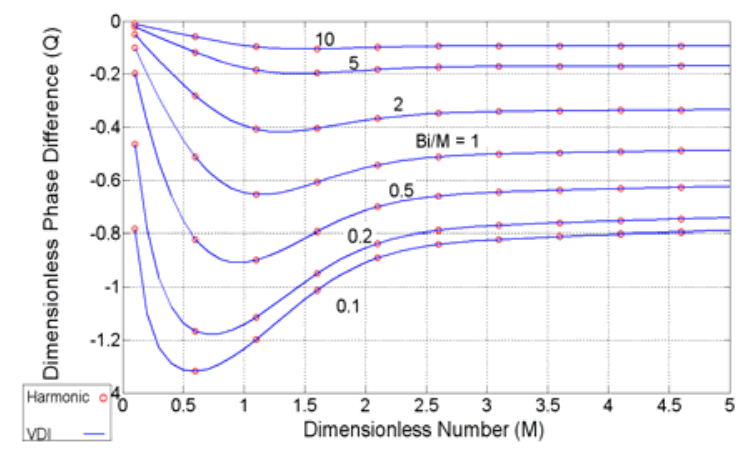

Fig. 2: Comparison between the result of the dimensionless phase difference, $\varphi$ of temperature field of a solid cylinder ${ }^{[4]}$ and our result

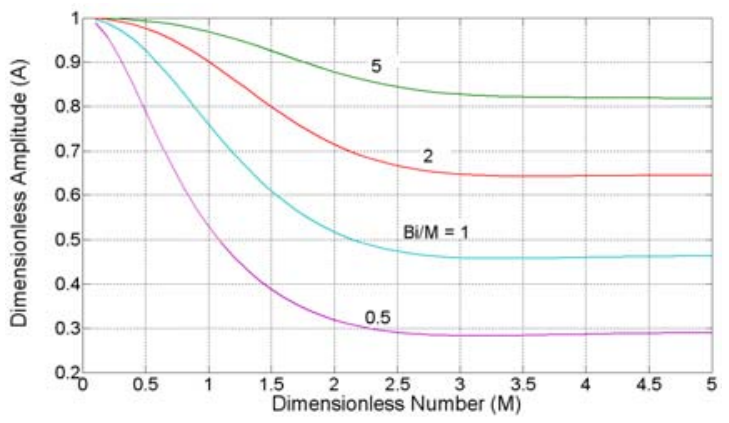

Fig. 3: Dimensionless amplitude, $\boldsymbol{A}$ when $\overline{\mathrm{r}}=1, \mathbf{m}=0.5$ 


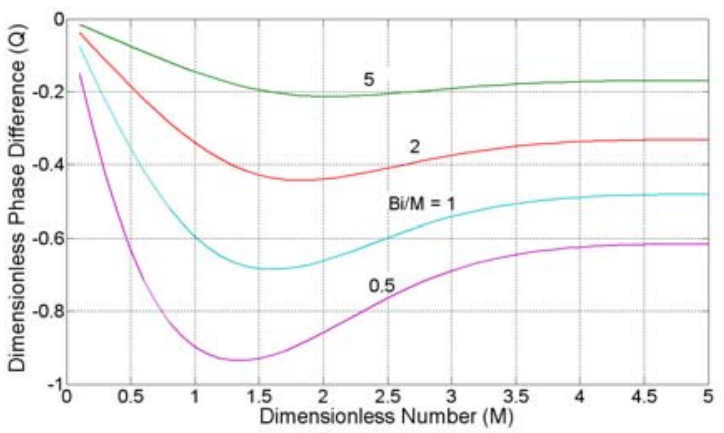

Fig. 4: Dimensionless phase difference, $\varphi$ when $\bar{r}=1$, $\mathbf{m}=0.5$

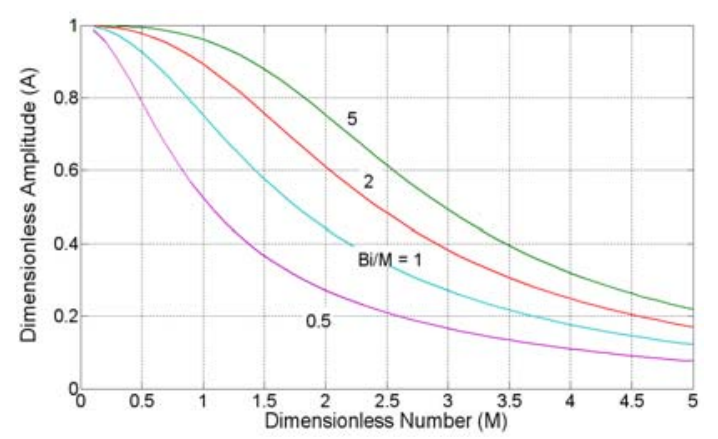

Fig. 5: Dimensionless amplitude, $\boldsymbol{A}$ when $\overline{\mathrm{r}}=0.7$, $\mathbf{m}=0.5$

As $M$ increases, the frequency of oscillations of ambient temperature become greater, the rate of energy storage becomes higher, the rate of heat conduction becomes lower, so, $A$ decreases. In this state the dimensionless phase $\varphi$ is negative. For great enough values of $M, A$ becomes constant and it shows in large frequencies and fast oscillations of ambient temperature the minimum and maximum of oscillations in hollow cylinder become constant and only a thin boundary of cylinder follows the ambient temperature.

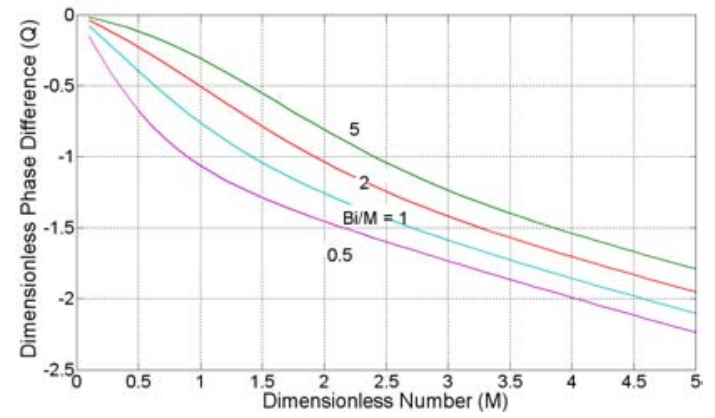

Fig. 6: Dimensionless phase difference, $\varphi$ when $\bar{r}=0.7$, $\mathbf{m}=0.5$

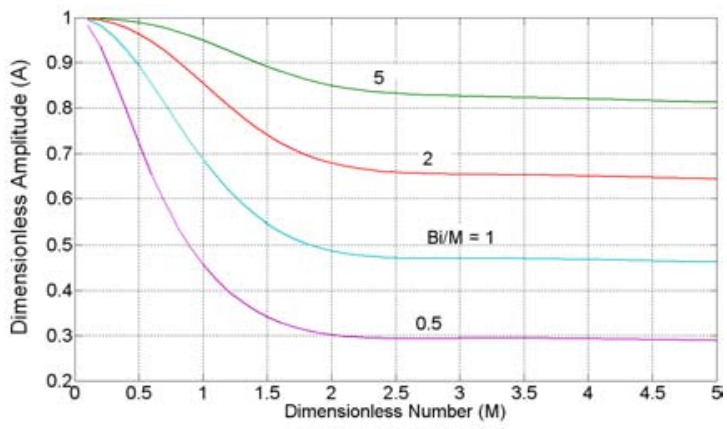

Fig. 7: Dimensionless amplitude, $\boldsymbol{A}$ when $\overline{\mathrm{r}}=1, \mathbf{m}=0.3$

The effect of dimensionless radius $(\overrightarrow{\mathrm{r}})$ on $A$ and $\varphi$ of temperature field: In Fig. 3 and Fig. $4 A$ and $\varphi$ of hollow cylinder, is plotted respectively. The assumed $m$, is 0.5 and $\overline{\mathrm{r}}$ is 1 . But in Fig. 5 and Fig. $6 m$ is 0.5 and $\bar{r}$ is 0.7 . Comparison between Fig. 3 and Fig. 5, show that with moving toward the center of hollow cylinder, $A$ decreases in same $M$. From Fig. 4 and Fig. 6 , it is clear that $\varphi$ becomes lower in same $M$. these effects are more dominant as $M$ increases.

The effects of dimensionless thickness (m) and (M) on $\boldsymbol{A}$ and $\boldsymbol{\varphi}$ of temperature field: In Fig. 7 and Fig. $8 \mathrm{~m}$ is 0.3 and $\bar{r}$ is 1 . In Fig 9 and Fig. $10 m$ is 0.99 and $\bar{r}$ is 1. Comparison between Fig. 7 and Fig. 9 show that with decreasing the thickness of hollow cylinder (increasing of $m$ ), $A$ in various $B i / M$ and same $M$, tends to 1 . Also, from Fig. 8 and Fig.10 it is clear that, with decreasing the thickness of hollow cylinder $\varphi$ tends to zero. These effects are more obvious when $B i / M$ increases. In Fig. 11 and Fig. $12 M$ is 2 and $\bar{r}$ is 1. In Fig. 13 and Fig. 14 $M$ is 4 and $\overline{\mathrm{r}}$ is 1 . Comparison between Figs. 11 and 13, show that, if $M$ increases, $A$, in various Biot numbers

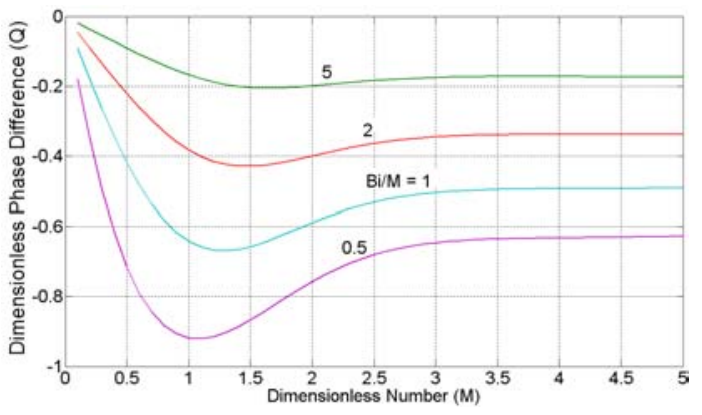

Fig. 8: Dimensionless phase difference, $\varphi$ when $\bar{r}=1$, $\mathbf{m}=0.3$ 


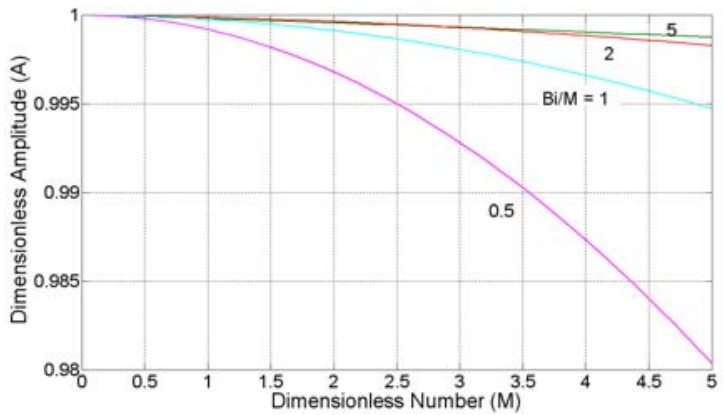

Fig. 9: Dimensionless amplitude, $\boldsymbol{A}$ when $\overline{\mathrm{r}}=1$, $\mathbf{m}=0.99$

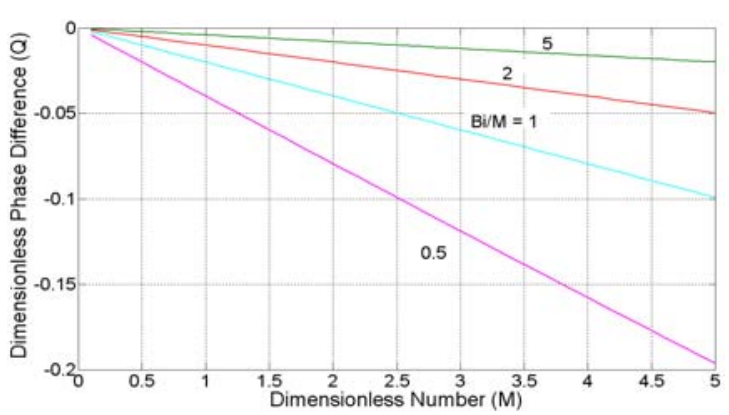

Fig. 10: Dimensionless phase difference, $\varphi$ when $\overline{\mathrm{r}}=1$, $\mathbf{m}=0.99$

and same $m$, decreases, Also, comparison between Figs. 12 and 14 show that, as $M$ increases, $\varphi$, in various Biot numbers and same $m$, decreases . Also, it is clear that, if $m$ increases, $A$ tends to 1 and $\varphi$ tends to zero.

The effect of dimensionless time $(\bar{t})$ on dimensionless heat flux: In Figs. 15-18, dimensionless heat flux with respect to dimensionless time is plotted. These figures show that, as Biot number increases, the value of dimensionless heat flux increases. In half a period the value of dimensionless heat flux is positive

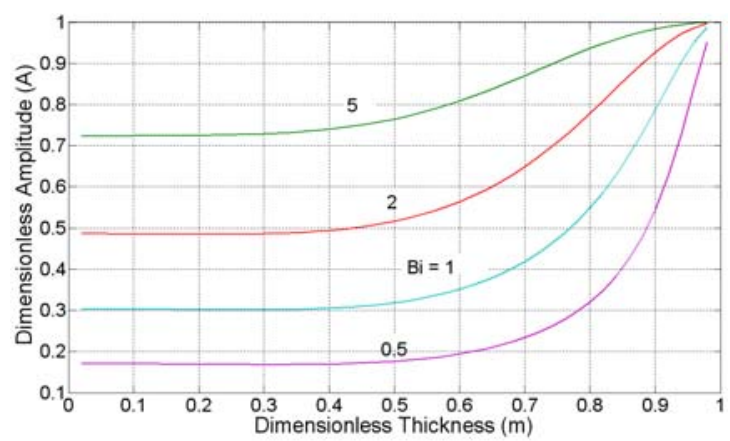

Fig. 11: Dimensionless amplitude, $\boldsymbol{A}$ when $\overline{\mathrm{r}}=1, \mathbf{M}=2$

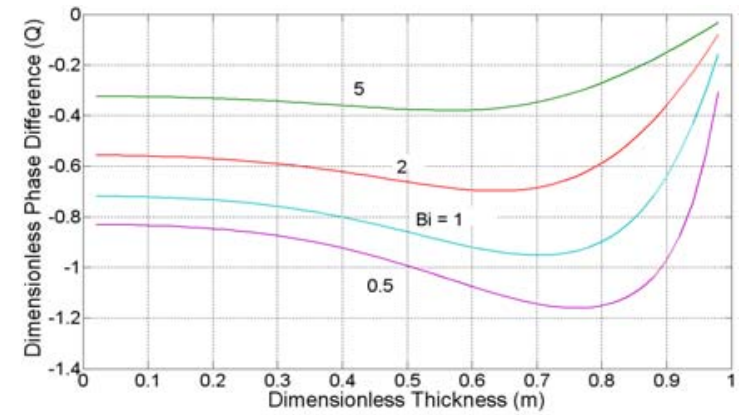

Fig. 12: Dimensionless phase difference, $\varphi$ when $\bar{r}=1$, $\mathbf{M}=2$

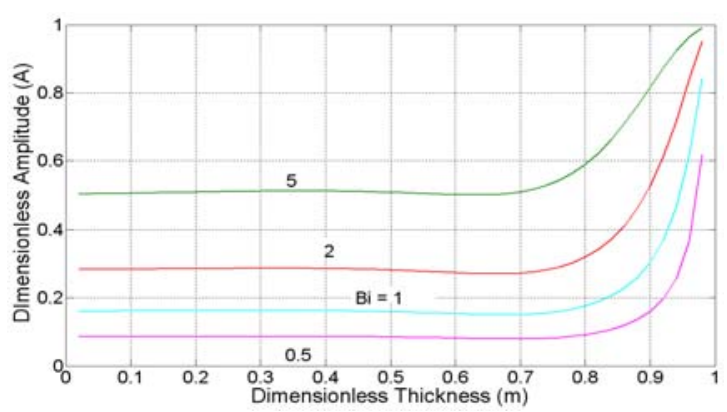

Fig. 13: Dimensionless amplitude, $\boldsymbol{A}$ when $\overline{\mathrm{r}}=1, \mathbf{M}=4$

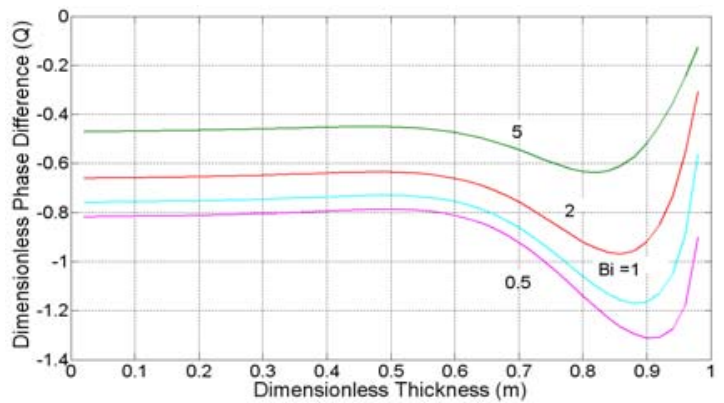

Fig. 14: Dimensionless phase difference, $\varphi$ when $\bar{r}=1$, $\mathbf{M}=4$

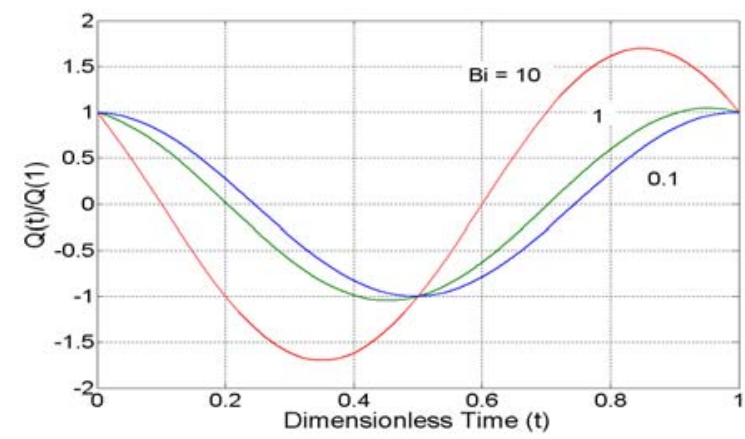

Fig. 15: $\mathrm{Q}(\overline{\mathrm{t}}) / \mathrm{Q}(1)$ when $\mathbf{M}=2, \mathbf{m}=.5$ 


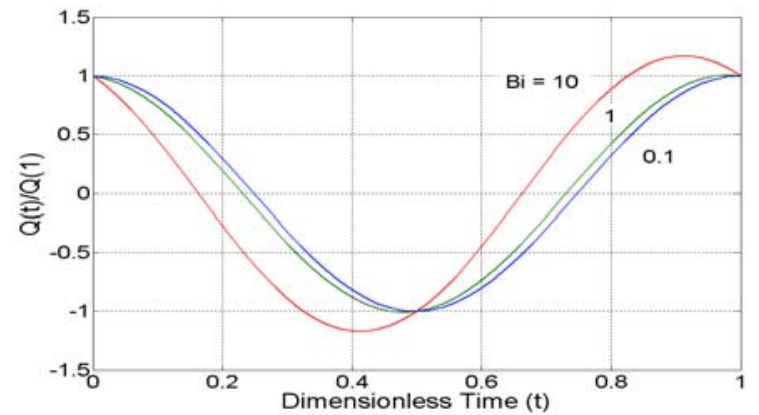

Fig. 16: $Q(\overline{\mathrm{t}}) / \mathrm{Q}(1)$ when $\mathbf{M}=4, \mathbf{m}=0.5$

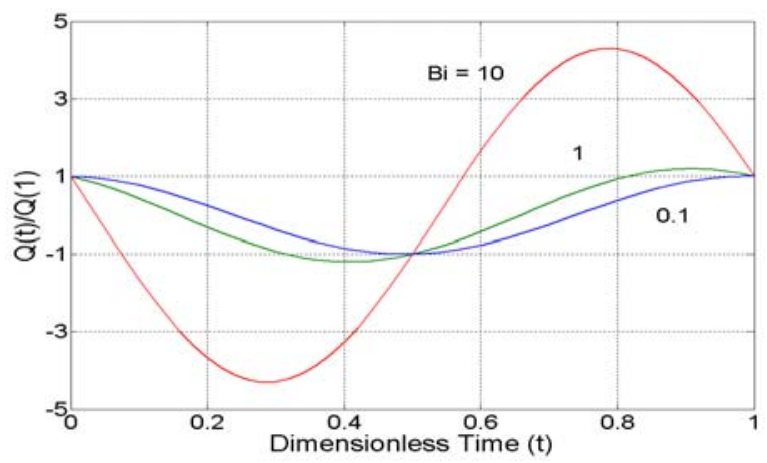

Fig. 17: $\frac{Q(\bar{t})}{Q(1)}$ when $\mathbf{m}=0.8, \mathbf{M}=2$

and in another half is negative. In Fig. 15 and Fig. $16 \mathrm{~m}$ is 0.5 . In Fig. 17 and Fig. $18 m$ is 0.8 . With comparison between Figs. 15 and 16, as $M$ increases, the dimensionless heat flux, decreases. This effect is obvious in Figs. 17 and 18. Also, comparison between Figs. 15 and 17 show that, as dimensionless thickness $(m)$ increases, the value of $\frac{Q(\bar{t})}{Q(1)}$ increases.

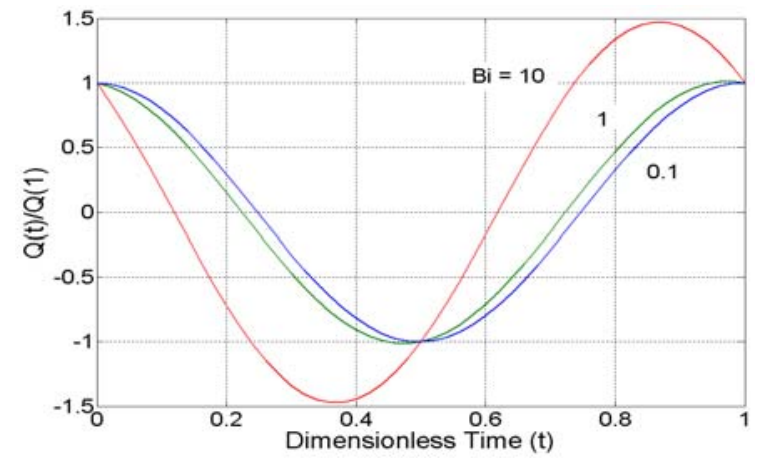

Fig. 18: $\frac{\mathrm{Q}(\overline{\mathrm{t}})}{\mathrm{Q}(1)}$ when $\mathbf{m}=0.8, \mathbf{M}=4$

\section{CONCLUSION}

The effects of various agents, such as $M, m, \bar{r}$ on $A$, and $\varphi$ discussed and the significant results obtained. These results represent in Fig.1-Fig.14. Also, in Figs. 15-18 the dimensionless heat flux plotted. Comparisons between Figures aid us to find more information about variation of these agents under time dependent periodic boundary condition.

\section{REFERENCES}

1. J.P.Holman. (1976), Heat Transfer, 4nd Ed., McGraw-Hill, USA, pp 109-152.

http://books.google.com/books?id=4QRRAAAAM

AAJ\&pgis $=1 \& \mathrm{hl}=\mathrm{en}$

ISBN 0070295980, 9780070295988

2. Özisik M. N. (1993) Heat Conduction, 2nd Ed, John Wiley, New York, pp 195-201.

http://books.google.com/books?id=LkGis_1erIIC

ISBN 0471532568, 9780471532569

3. Trostel R. (1956) Instationäre Wärmespannungen in einer Hohlkugel, Ingenieur-Archiv, pp 373-391.

DOI: $10.1007 / \mathrm{BF} 01845967$

http://www.springerlink.com/content/u001x334446 $04 \mathrm{~g} 55$

4. Verein Deutscher Ingenieure (VDI)-Wärmeatlas, 2003, Ed 14-17, Düsseldorf.

ISBN 3540437126, 9783540437123 